\title{
Diário de Classe
}

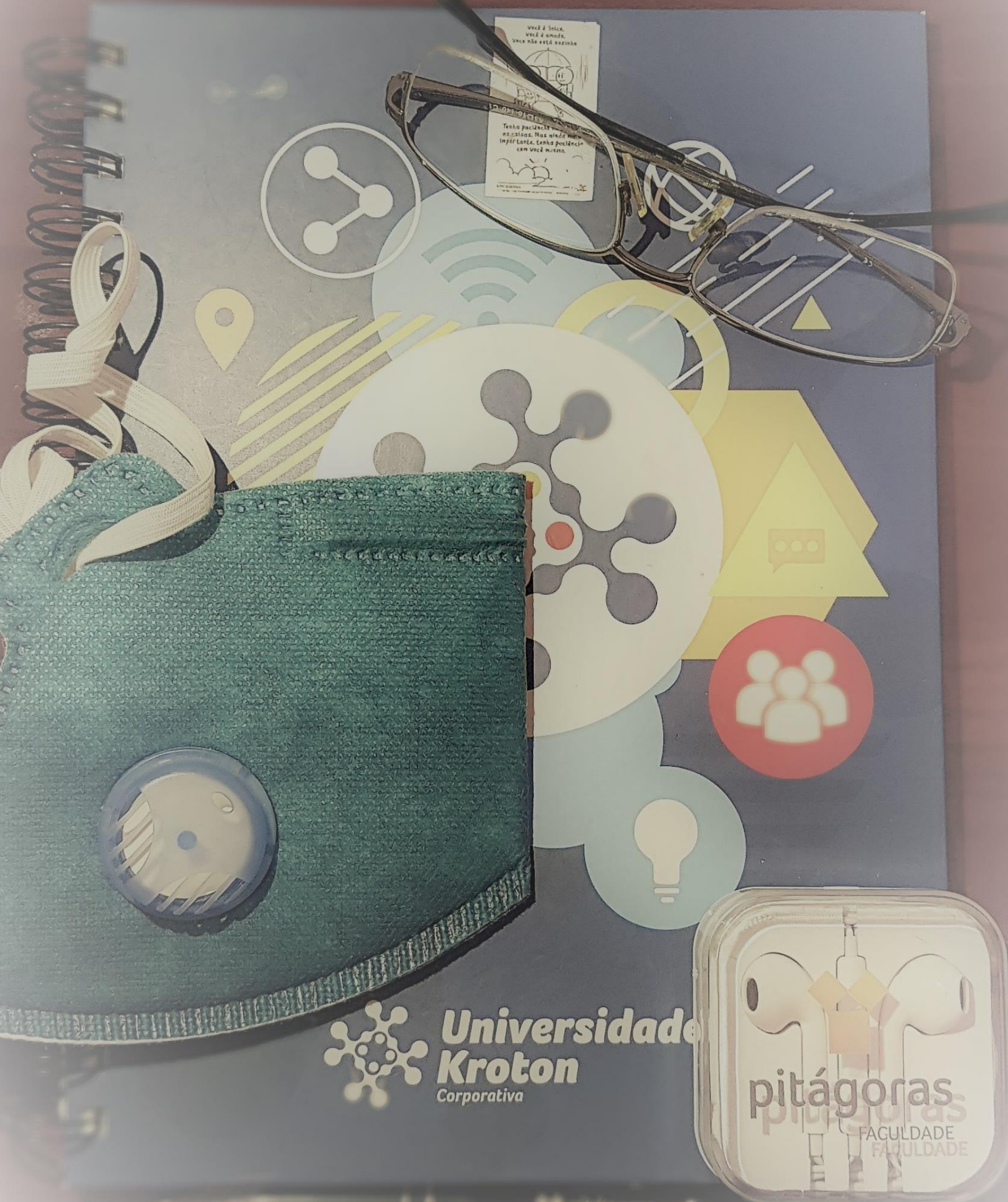




\section{Diário de Classe}

\section{Organizadores}

Eduardo Brandão Azevedo

Raquel de Oliveira Torres

Dados Internacionais de Catalogação na Publicação (CIP)

D539 Diário de classe/ Eduardo Brandão Azevedo, Raquel de Oliveira Torres (organizadores) - Belo Horizonte, 2020. $43 \mathrm{p}$.

1.Covid-19 2. Diário 3. Pandemia I. Título. II. Azevedo, Eduardo Brandão III. Torres, Raquel de Oliveira IV. Faculdade Pitágoras

CDU 808.833 


\section{DEDICATÓRIA}

Dedico este livro aos inúmeros diários presentes no mundo e aos diversos autores que os enriquecem com suas vidas e segredos. Todos os diários são mestres que ouvem sem nunca responderem, mas mesmo assim nos engrandecem, confortam e nos fazem entender quem somos. 


\section{AGRADECIMENTOS}

Cada registro somente foi possível devido ao comprometimento dos participantes e, sendo assim, seguem nossos agradecimentos aos formandos de fisioterapia que se dispuseram a fazer o diário e, em especial, pela contribuição aqui dispensada como colaboradores ao autorizar a divulgação de trechos de seus respectivos diários:

Agder da Silva, Aline Mendes, Amanda da Silva, Ana Carolina Santana, Ana Cláudia Martins, Bárbara Damascena, Beatriz da Cruz, Brenda Domingos, Bruna Moreira, Célia Gomes, Daiane Botelho, Daniel Martins, Daniel Teixeira, Dayane Nicácio, Elaine de Calais, Fernanda Machado, Irene Vinhal, Jane dos Santos, Jéssica de Morais, Jéssica Machado, Juliana da Silva, Karine dos Reis, Lilia Souza, Lucimar Couto, Natália de Oliveira, Rafaela Costa, Samara Rodrigues, Simone Mendes e Tatiana Ciúves.

Não podemos nos esquecer dos nomes dos diários criados por alguns destes colaboradores neste processo de criação e retroalimentação:

Belinha, Christopher, Colega, Diário, Enzo, Estrela, Hope, Jack, Lilac, Lu, Maia, Molly e Sabiá.

À todos os professores, alunos, gestores e funcionários que possibilitaram as atividades acadêmicas fossem mantidas, mesmo com todos os desafios que foram sendo vencidos um-a-um, um dia de cada vez.

À Raquel de Oliveira Torres que teve a disponibilidade em ser organizadora e colaboradora nesta empreitada.

Agradeço ao nosso Pai celestial que provê, mesmo nos desafios, aprendizado e superação. 


\section{EPÍGRAFE}

Este livro foi concebido após registro realizado pelos acadêmicos do último período de Fisioterapia da Faculdade Pitágoras - Unidade Guajajaras (turma de formandos 20201) durante atividade proposta pelo autor. A atividade foi a de montar um diário entre os dias 12 de maio e 12 de junho de 2020, no qual cada acadêmico relataria o que se passava em seu cotidiano durante a pandemia.

Para tanto, foi solicitado que todos lessem o livro "Diário de Anne Frank" para que, desta forma, pudessem entender melhor a situação da protagonista da história e, em seguida, pudessem assimilar e registrar o contemporâneo, haja vista algumas similaridades entre ambas as situações (guerra mundial versus pandemia).

O título deste livro surgiu ao final da sua confecção e, por ter múltiplos significados, cabe a cada leitor interpretá-lo ao seu modo. Importante ressaltar que este livro foi baseado nos relatos colhidos aleatoriamente, sendo cada dia baseado no relato de um acadêmico diferente e não houve acesso ao que outrem escrevia e, tão pouco, correções ortográficas ao que escreveram. Portanto, este registro pode exemplificar, pelo menos, um dia aleatório do cotidiano de cada um dos acadêmicos formandos de fisioterapia durante a pandemia entre os meses de maio e junho de 2020 e que tiveram interesse em autorizar sua divulgação. Outros desdobramentos e outras interpretações poderão ocorrer de forma a dar-nos possibilidades diversas e, seu uso ético, acadêmico e científico será sempre bem-vindo para qualquer leitor. 


\section{SUMÁRIO}

PREFÁCIO

DIÁRIO DE CLASSE .................................................................................

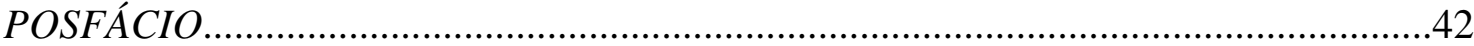






\section{PREFÁCIO}

Antes de tudo, foi solicitado aos acadêmicos que lessem o "Diário de Anne Frank". Mas quem foi Anne Frank e quais foram nossas observações e impressões sobre o seu diário?

Annelies Marie Frank nasceu em Frankfurt no dia 12 de junho de 1929 e supostamente faleceu entre fevereiro e março de 1945. Sua origem, portanto, é judaicoalemã.

Durante a Segunda Guerra Mundial entre 1933 e 1934 sua família se mudou para Amsterdã fugindo da guerra e lá residiu adaptando-se à constante perseguição judaica imposta pelos alemães. Mas em julho de 1942 tiveram que se esconder do regime político antissemita que intimou sua mãe a se apresentar à SS alemã. Coincidência ou não, no dia 12 de junho do mesmo ano Anne havia ganhado de aniversário um diário para escrever seu cotidiano. E é esse registro impressionante de uma adolescente de 13 a 15 anos, perseguida e confinada em plena Guerra que nos inspirou e que ainda irá inspirar tantos.

Ficaram 8 pessoas isoladas e sobrevivendo em um edifício comercial na capital da Holanda desde julho de 1942 até agosto de 1944 quando os nazistas descobriram seu esconderijo e, desmantelando a família, os mandaram para campos de concentrações nazistas diversos. Destes, o único sobrevivente foi o pai de Anne, Otto Frank que retornou à Amsterdã após a Guerra. Lá ele pôde se encontrar com Hermine Gies, cujo apelido carinhoso era Miep. Miep trabalhou com Otto antes de se esconderem no sótão do fatídico prédio comercial, além de ajudar no processo de mudança e de manutenção da saúde de todos, pois a mesma era secretária e contadora no edifício. Quando os nazistas levaram a família Frank, família Van Daan e o Dr. Dussel para os campos, a mesma recuperou a maioria dos pertences de todos e inclusive o diário de Anne Frank e desta forma, pôde entregar ao seu pai quando este retornou à Amsterdã. Com diário em mãos e, com muito custo e insistência, pôde publicá-lo em 25 de junho de 1947 (primeira publicação).

Em 1959 foi filmado filme intitulado Diário de Anne Frank (baseado no livro) que inclusive recebeu 3 óscares. Além disso, foi inaugurado em 1960 um museu no prédio onde ficaram confinados recebendo uma estatueta de Anne e que recebe milhares de visitantes anualmente. A revista Time a considera ícone do último século. 
Ela e sua irmã Margot Frank foram levadas por fim há um campo de concentração chamado Bergen-Belsen que fora criado em 1940 para prisioneiros de guerra. Somente em 1942 tornou-se de concentração e foi assumido pela SS em 1943 não tendo câmara de gás. Provavelmente morreram de febre tifoide (TIFO) devido desnutrição, trabalhos forçados e frio, assim como milhares de outros semitas. Algumas semanas após a sua morte e de sua irmã Margot, os britânicos libertaram o campo de concentração e constataram os horrores do holocausto, tortura, maus tratos e a infâmia.

Atualmente o campo de Bergen-Belsen é aberto à visitação e é possível ver um obelisco feito e mantido em homenagem às vítimas do holocausto.

Existem inúmeras interpretações do diário de Anne Frank que podem se dar devido às versões e traduções do mesmo. Mas para a atividade proposta, tivemos ao final da realização do diário, uma discussão em grupo e eu, juntamente com os acadêmicos chegamos à algumas suposições.

O primeiro levantamento ou curiosidade é o motivo de Anne Frank não criar o seu próprio diário. Ela ganhou o mesmo de presente e, além disso, assume em seu registro que não era de seu desejo inicial ter um diário. Portanto, especulamos que a mesma, por ser introspectiva em relação aos sentimentos e por entrar na puberdade, foi presenteada pelo pai afim de poder desabafar e escrever sobre seus sentimentos. Como a mesma amava muito seu pai, se permitiu usá-lo e passou a gostar de fazê-lo com o tempo.

O primeiro registro em seu diário sobre o confinamento que iria ocorrer se dá em 8 de julho de 1942 onde escreveu sobre a visita dos representantes da SS à sua casa. Nesta ocasião ela cita Miep, que seria fundamental no desenrolar de toda esta história, possibilitando inclusive a publicação do livro de Anne Frank.

Durante a leitura do diário, outras características de Annelies nos saltam aos olhos, como, sempre que a mesma apresentava angústias e anseios em demasiado, ela escrevia com mais frequência, como para ter um refúgio, conforto ou forma de lidar com estas demandas. E supostamente quando ocupava a mente com leituras ou traduções, a mesma escrevia raramente em seu diário. Seria esta uma suposição enganosa?

Outra característica interessante é que a mesma por diversas vezes se confundia em qual dia da semana era no início de cada registro. Exemplo, dizer que é domingo, sendo 
que é segunda-feira. Chegamos à conclusão que isso pode ser em decorrência do próprio confinamento ou que, às vezes, ela registrava em dias diferentes do fato ocorrido.

No natal de 1942 não houve registro, mas no natal de 1943, onde houve problemas e insatisfações, a mesma se dispôs a escrever em seu diário, indicando talvez uma tendência em usar o diário como válvula de escape para insatisfações.

Em 1 de abril de 1943 ela cita a fatídica brincadeira do dia da mentira e nos questionamos de onde é a origem de tal anedota. Por outro lado, em 1 de abril de 1944 ela se declara para Peter Van Daan explicitamente. Seria isso uma estratégia de escrita para que se alguém visse o diário ela pudesse dizer que era por causa do dia da mentira?

Seu último registro no diário, em 1 de agosto de 1944 foi muito melancólico e esclarecedor, demonstrando uma possibilidade de distúrbio emocional insipiente e demandas para serem administradas em sua psique.

Então, devemos nos perguntar se a mesma desenvolvia um quadro psíquico supostamente alterado devido também ao confinamento? Ou será que a mesma já tinha esta tendência até mesmo por ter recebido de presente um diário para poder desabafar? E a perseguição e a Guerra? Como influenciaram esta adolescente? Seria ela uma frágil mulher ou uma forte garota? Saber isso realmente importa? Que cada um de nós cheguemos às nossas conclusões. Não nos esqueçamos que ela tocou o coração de todos que puderam ler seu diário e emocionou àqueles que puderam ser cúmplices de seus segredos.

Quanto ao cenário atual, estamos em meio à uma pandemia. Receios, necessidades, confinamento, falta de perspectiva e angústias podem permear o pensamento e as ações de várias pessoas no mundo. Pessoas de todas as idades vem sofrendo por causa do COVID-19 e não necessariamente são aqueles já acometidos pelo vírus. Mas também aqueles que devem se isolar e se confinar sem sua vontade ou desejo. Então há inúmeros doentes que sofrem e que dependem de outros que podem ter suas demandas emocionais.

E os alunos formandos, com seus sonhos, anseios e demandas que estavam há alguns meses de se formarem? Como ficam seus pensamentos e sentimentos com isto tudo? Há similaridades entre o confinamento de Anne Frank e o confinamento pela pandemia de COVID-19? 


\section{DIÁRIO DE CLASSE}

terça-feira, 12 de maio de 2020

Olá. Seja bem-vindo! Sou Eduardo, o professor.

Te criei, pois, em março de 2020 uma pandemia que está assolando o mundo com um vírus denominado COVID-19 chegou até a capital de Minas Gerais, cidade onde resido. Neste nosso lindo país, o Brasil, bem como em todo o mundo, tivemos que nos confinar em nossas residências saindo apenas quando necessário. Este cenário me fez lembrar de Anne Frank que em 1942, em plena Guerra Mundial, criou um diário vivendo em confinamento. Ela deu-lhe o nome de "Kitty".

Pedi, então, aos meus acadêmicos que fizessem uma atividade. Tal atividade foi a de relatar em um diário tudo que tivessem interesse entre os dias 12/05 e 12/06/2020. Além disso, pedi que lessem o livro "Diário de Anne Frank". Quem sabe os frutos que teremos desta atividade? Talvez o tempo saberá.

Seu nome será Christopher. Nestes 31 dias irei confidencializar tudo que ocorrer comigo, bem como pensamentos, sentimentos, fatos e situações. Tenho certeza que você será de grande conforto para mim, bem como os outros diários para os seus respectivos acadêmicos. 
quarta-feira, 13 de maio de 2020

Escrever aqui não é fácil hein! Não é fácil estar sempre neste estado de ansiedade e as vezes a cabeça dá um nó.

Quero estudar e ocupar minha mente com outros assuntos, mas eu me pego questionando a mim mesma, para quê estudar mais, você nem sabe que dia vai voltar para o estágio?!

E então fica inevitável segurar as lágrimas e é tanto curso, tanto tempo e tanta dedicação para, no final, bem no final, acontecer tudo isso. 
2020 chegou, como todo bom brasileiro, gozamos de festas, alegrias, comemorações e todos esperando o tão sonhado carnaval. Para muitos, diversão, já para outros nem tanto, eu, por exemplo, não gosto.

Em fevereiro já havia rumores da doença, mas para o povo isso nunca faria parte da nossa realidade, foi quando apareceram os primeiros casos e com eles a grande preocupação. Começaram os desesperos e enfim mergulhamos no caos que nos encontramos hoje. Vivemos dias de medo, insegurança dúvidas e incertezas, estamos vivendo um filme de terror.

Os dias não são como antes, não se ouvem as pessoas falarem algo concreto e agora cada um se agarra no que pode... então só nos resta esperar em Deus, ele é nossa única saída e o tempo nos trará a resposta. Enquanto isso ficamos em casa e aproveitamos nosso tempo para colocar nossa vida e nossa casa em ordem.

Começaram fechando as escolas depois bares, praças, shoppings, teatros, praias, aeroportos, rodoviárias, cancelaram os voos, fomos separados dos amigos, parentes, não há mais contato físico e agora todos são obrigados a usar máscaras. 
sexta-feira, 15 de maio de 2020

Colega, o marido chegou com compras do supermercado e sabe qual a próxima etapa? Higienizar tudo... nunca imaginei em minha vidinha que iria dar banho num pacote de arroz antes de guardar no armário... Sempre higienizei as frutas, verduras e legumes devidamente antes do consumo, mas, embalagens é uma nova tarefa na rotina. 
sábado, 16 de maio de 2020

Bom dia.

Hoje aprendemos a fazer uma deliciosa torta de abacaxi com côco. Fiz e ficou um sucesso. Em seguida comecei a procurar as respostas do exercício que o Professor Brandão pediu para que fizéssemos e em seguida precisei sair para resolver algumas coisas. Lembrei da segurança.

Retomei a leitura do livro "A paciente silenciosa". 
Hoje acordei um pouco mais leve que ontem, mas ainda muito angustiada e nervosa. Hoje depois de muito tempo em casa sai para ir ao supermercado e vi como as pessoas não estão tendo noção da gravidade da situação em que estamos vivendo, pois vi várias pessoas andando na rua sem máscaras na maior tranquilidade como se estivesse tudo normal, não respeitam as normas de distanciamento das outras pessoas, ficam todas emboladas nas filas, levam crianças para as ruas sem necessidade. Então hoje acabei vendo que talvez este confinamento dure mais tempo do que está sendo esperado pois para isso acabar logo, todos nós temos que ter consciência e vi que não é isso que está acontecendo. Hoje também vi minha querida amiga Jane, ao mesmo tempo que fiquei feliz em vê-la, fiquei triste pois tive que conversar há metros de distância sem poder abraçar ou ficar um pouco mais perto dela. Que triste realidade estamos vivendo. Quando isso vai acabar? Quando vamos voltar a nossas vidas normais? Quando irei poder abraçar e beijar meus familiares e amigos de novo? Por hoje é só, até amanhã. 
segunda-feira, 18 de maio de 2020

Estou me sentindo melhor. Dormi bem e acordei mais animada, mais alegre.

Hoje já fiz minhas atividades do AVA, pratiquei exercícios com meus filhos e me alimentei bem.

Dei continuidade aos meus cursos online mas ando preocupada com os resultados dos exames que irão ficar prontos dia 21/05. Agora estou tendo que tomar 4 tipos de medicamentos. 
Olá Hope, como já havia dito anteriormente, você é parte da minha vida agora e uma coisa que você deve saber é que nem sempre estou disponível, mesmo que seja algo interessante. Se eu acreditasse em horóscopo poderia dizer que a culpa é do meu signo ou do meu ascendente. Mas a verdade é que principalmente agora neste período que estamos vivendo meu desinteresse está cada vez maior. A vida parece um quadro de Picasso sem as cores. Na verdade, se eu fosse descrever a vida através de um pintor com certeza seria o realismo de Caravaggio com o surrealismo de Dali, tudo junto.

Quando foi proposta essa atividade de transcrever através de linhas o meu sentimento fui completamente contra (e continuo sendo contra). Mas outra característica minha é que vivo lutando contra mim mesmo e a possibilidade de fazer algo novo me fez mudar de ideia. Nestes dias que o mais próximo de contato que eu tenho é com o Scott (já falei que tenho um doguinho?). Ter alguém pra "conversar" me fez mudar por um estante de ideia e aqui estou eu. Bom, de novo não tenho nada. Meus dias se resumem em acordar, ir para o trabalho que são exatamente cinco passos da minha cama (eu parei o texto para contar o número de passos). Trabalhar, arrumar a casa e cuidar / brincar com Scott e às $16 \mathrm{~h}$ meu amor chega em casa (contei que sou casado? Sou casado há 4 anos). Fazemos janta (eu faço) vamos para cama brincar com o Scott e ver algumas mídias sociais e depois dormimos. Isso resume meus dias durante essa quarentena, com pouquíssimas variações. Recentemente fui surpreendido com uma notícia de uma vacina para este vírus. Mas continuo acreditando que ainda estamos longe de voltar à normalidade.

Pois é Hope, a cada dia está ficando mais difícil encontrar alguma esperança e dizer que dias melhores virão está ficando cada vez mais sem força. A esperança está cada vez mais escassa e pensar em algo bom também. Quem sabe algum dia poderemos olhar essas páginas e "rir" de tudo isso? 
Hoje acompanhei pelas redes sociais anônimos e artistas manifestando contra a morte de um adolescente que perdeu a vida. Ele foi baleado e morto durante uma operação da Polícia Federal no complexo do Salgueiro em São Gonçalo - RJ. Mais uma criança que perde a vida sem ao menos se defender. Até quando vamos acordar com notícias assim? Muito triste.

Fui no supermercado comprar algumas coisas que estavam faltando, prefiro ir na parte da manhã pois tem menos gente. Evito de pegar filas. Outro dia fui à noite e peguei uma fila enorme para entrar. As pessoas não respeitam a distância, com medidas de proteção orientadas pela OMS os supermercados estão controlando a entrada de clientes através de placas com números, uso de álcool nas mãos é obrigatório para recepcionar os clientes, o uso de máscaras também é obrigatório. Sem máscara o cliente não consegue entrar. No final do dia Wagner e eu fomos caminhar. Geralmente fazemos $9 \mathrm{~km}$ pois próximo de casa tem uma pista para caminhada. Até a próxima! 
Passei toda a manhã fazendo visita domiciliar, porém a orientação do momento é que não entrássemos no domicílio. Muitos pacientes ainda não compreendem a necessidade desse distanciamento. Acho que a solidão também os tornam carentes de atenção. Quando cheguei na unidade de saúde tinha um recado em minha mesa para que comparecesse às 13H na secretaria de saúde para reunião. Assim eu fiz. 13h estava lá. Nos foi passado que no dia 22 de maio começará o trabalho de uma barreira sanitária no município, naquele momento foi me passado uma escala com nomes e horários que estaríamos atuando nos locais de saída e entrada do município. Ao meu ver essa barreira não seria eficaz, pois até o momento o município não conta com termômetros, panfletos, máscaras em quantidade suficiente aos profissionais. O propósito seria bloquear a entrada de carros com placas de outros municípios, porém os veículos de nossa cidade circulam livremente para outras cidades, vão e voltam sem sequer orientações e abordagens de onde estiveram, como se estivessem livres de tudo. Sinto que essa ação é mais uma "para inglês ver". 
sexta-feira, 22 de maio de 2020

Comprei produtos que faltavam para repor o estoque do meu pão de alho. Não lembro se comentei, mas o meu pão é "recheado de bom gosto", fiz rede social e tudo está muito bonitinho. Beijo Lilac. 
sábado, 23 de maio de 2020

Querida Maia, Bom dia!

Pensa num sono daqueles e ainda são 07:13H da manhã, mas o motivo de estar acordada é muito bom.

Hoje começa o I Simpósio beneficente de Fisioterapia Neurofuncional online. Dentre as várias palestras terá uma que estou muito ansiosa que será com a linda, maravilhosa, sensacional e incrível Dra. Ana Clara. Benefícios da equoterapia para crianças com deficiência. Beijo! 
domingo, 24 de maio de 2020

Mais um dia igual aos outros confinada em casa, sem fazer nada. Ufa que preguiça. 
segunda-feira, 25 de maio de 2020

Não consigo escrever regularmente. Aqui mesmas coisas acontecendo. Ficando em casa fazendo cursos online e assim esperando que o tempo passe logo para retornar.

Escuto música, retomei o hábito de ler assuntos fora do contexto da faculdade. Conhecimento ninguém rouba e agora com tempo de sobra não justifica não aproveitá-lo da melhor forma.

Hoje recebi uma ligação dizendo que fui aprovada em processo seletivo da Prefeitura de onde moro. Ufa vou ocupar a cabeça e ser útil fora de casa. 
terça-feira, 26 de maio de 2020

Querido papai,

Falar de você é falar de mim. Somos tão parecidos, mas ao contrário do que todo mundo pensa eu não acho isso ruim. Você é um cara firme que nunca se deixa abalar e sabe equilibrar a razão e a emoção para agir na hora certa. Você é o pilar da nossa família e mesmo com esse jeitão, sei que lá no fundo tem um coração enorme que não cabe no peito de tanto amor que tem dentro dele. Te amo. 
quarta-feira, 27 de maio de 2020

\section{Boa noite!}

Hoje descobri que escrever todos os dias no diário tem me proporcionado uma reflexão que antes não existia, talvez pela correria, mas ao escrever é possível colocar para fora os sentimentos, sejam eles bons ou ruins, é fazer você um protagonista e tentar mudar algo no dia seguinte. Escrever tem sido muito bom até mesmo para pontuar o que é bom ou ruim. Hoje está sendo um dia tranquilo. Não tenho novidades mas estou com saúde e bem. 
quinta-feira, 28 de maio de 2020

Querida Lu,

Hoje foi corrido.

As atividades acadêmicas consumiram o meu dia, mas está tudo bem. 
sexta-feira, 29 de maio de 2020

Querido Diário,

Minha best friend hoje veio passar o fim de semana conosco e havia muito tempo que ela não aparecia. Acordei cedo, fiz uma faxina a tarde, fui encontrar ela no centro de BH e aproveitar para comprar algumas coisas de uso pessoal. Fiquei chocada com a quantidade de gente nas ruas. As lojas estão tomando as medidas de proteção com uso de álcool, ficha para controlar a quantidade de clientes.

Fui com medo, mas usando máscara e meu álcool na bolsa. Passamos no supermercado hoje e nossa janta foi cachorro quente. Após o jantar fomos assistir à um filme. Que filme ruim! Foram 2 horas e 15 minutos de perda de tempo! 
sábado, 30 de maio de 2020

\section{Oi Jack!}

Sabadim de folga. Aproveitei para arrumar a casa. 
domingo, 31 de maio de 2020

Hoje me senti muito indisposta e com muita dor de cabeça (acho que a enxaqueca me pegou de jeito).

Infelizmente hoje não consegui produzir muita coisa. 
Querido diário, hoje como todos os dias minha mãe, para não perder o costume, sempre me acorda bem cedo. Então levantei, tomei meu café assistindo um jornal da globo que eu adoro, depois de um tempo então começou a melhor parte, rsrssrsrs, brincadeira. Fui arrumar a casa em quanto minha mãe lavava roupas, arrumei casa, limpei a casinha da minha cachorra, limpei o terreiro e depois fui arrumar almoço. Fiz almoço e fomos almoçar por volta das $13 \mathrm{~h}$. Depois vi o jornal e aproveitei para dar uma "dormidinha", pra não perder o costume. Por incrível que pareça, eu dormi tanto que fui acordar as $18 \mathrm{~h}$. Já estava escuro quanto acordei e até assustei. Geralmente minha mãe vai atrás de mim para me levantar (ela não sabe ver agente quieta kkk), então levantei e fui pra sala para conversar com ela enquanto víamos tv. A tv em casa fica ligada quase o dia todo e conversamos até aproximadamente 20:45h. Assisti o resto do jornal e depois via a novela. Depois fui deitar e dessa vez não dormi no sofá rsrsrs. Por hoje é só.... 
terça-feira, 02 de junho de 2020

30.077 mortos é o nosso número hoje. Meu Deus quantas pessoas sofrendo neste momento de casos confirmados já são mais de 530.733 no Brasil. Como é triste saber que estes números podem ser ainda maiores, pois é e o boato que está rolando nas redes é de que estes números são atualizados com atraso e muitos ainda dizem ser uma gripezinha, outros dizem que não serão pegos por ela. Eu permaneço com muito medo e me cuidando. Bom passei o final de semana ocupada com as atividades online da faculdade. Hoje pela manhã tive de ir ao mercado. Fui também na farmácia e confesso que fui também em uma loja de festas que estava vazia. Fui adiantar meu presente de dia dos namorados que será comemorado em casa com um pouco de mimo. Falando nisso, Eduardo voltou a trabalhar no escritório ontem causando muito estresse em nós. Mesmo com todas as medidas sendo tomadas. Providenciei uma máscara hospitalar N95, muito álcool na mochila, além de luvas e máscara extra, troca de roupa quando chega no trabalho e quando chega em casa. A roupa e sapatos começam a ser retirados do lado de fora de casa e já vai direto para o chuveiro e as roupas para a máquina. Essa é nossa rotina, infelizmente no momento. Continuamos pedindo a Deus que isso mude. 
quarta-feira, 03 de junho de 2020

\section{Querida Estrela!}

Hoje comecei bem cedo o dia. Acordei às $6 \mathrm{~h}$ da manhã por causa do barulho da cachorrada daqui de casa. Aff! Ninguém merece.

Bom, mas já que acordei agora e não vou conseguir dormir mais um pouco, vou aproveitar para adiantar algumas coisas da faculdade agora pela manhã. Acabei de abrir mais uma atividade proposta por um dos professores. Nossa! Coisa demais Jesus! As vezes parece que os exercícios e a faculdade nunca terão fim. E por falar em faculdade, esse mês se não fosse a pandemia estaria concluindo meu curso. Estou um pouco triste por conta disso. Queria muito concluir agora. Chega um momento que a gente já está cansada esgotada, entende? E eu estou desse jeito. Mas não posso desistir agora faltando tão pouco.

Mas mudando de assunto estava pensando em fazer algo diferente pra poder passar o tempo, por que ultimamente a única coisa que tenho feito bastante é estudar e só. Não tenho tido muita distração. Será o que há de se fazer só em casa? Não faço idéia. Estou pensando muito pouco (risos). Acho que vou reler pela terceira vez " $\mathrm{O}$ diário de Anne Frank”. Vou começar hoje mesmo.

Vou organizar também os álbuns de fotografia da família. Outro dia até revi com minha mãe lembra? Mas não colocamos em ordem.

Por fim acho que vou fazer mais docinhos pra vender. O pessoal que comprou anteriormente gostou tanto. E por ser uma coisa que já gosto de fazer, será um ótimo passatempo. Estrela, vou ficando por aqui. Até! 
quinta-feira, 04 de junho de 2020

Depois de um bom tempo sem escrever voltei!

Estava desanimada.

Por aqui está a mesma coisa, ainda sem cura para esse vírus.

Economia no buraco.

Só Deus na causa. 
sexta-feira, 05 de junho de 2020

Olá. Conversei muito com meu namorado, minhas amigas pois eu e o Diego vamos ficar noivos. Até que enfim. Há, há há!

Depois de 9 anos de namoro decidimos dar mais este passo nas nossas vidas.

Um cheiro. 
sábado, 06 de junho de 2020

Fim de semana bem tranquilo, passei na casa do meu namorado. Não fizemos nada de diferente. Fizemos almoço juntos, brigadeiro, assistimos filmes, foi muito bom. Sábado de muita risada e amor. 
domingo, 07 de junho de 2020

Hoje venho aqui te atualizar meu querido diário...

É com o coração partido que te escrevo, infelizmente meu querido e amado vovô faleceu...

Dia 06, no fim da tarde ele se foi... morar com Deus.

Eu não entendi até agora, mas confio em Deus!

A dor é imensa, parece que foi tirado de mim um pedaço do meu coração...

Mas sei que ele descansou, e agora está nos braços do Pai.

Te amarei eternamente vô!! 
segunda-feira, 08 de junho de 2020

Boa noite querido Enzo.

Continuo na saga da apresentação do meu TCC e meu dia se resumiu em ficar no quarto para montar a apresentação para a banca e descobrir como fazer a gravação para a banca avaliadora.

Meu computador não está colaborando comigo, mas já adiantei bastante coisa e seguimos firmes. 
terça-feira, 09 de junho de 2020

Hoje é o aniversário da minha vizinha que considero como avó. Ela está completando seus 70 anos e queria poder lhe dar um abraço, mas como estamos vivendo o terrível e necessário isolamento social. Além disso, nós duas somos do grupo de risco. Mas apesar do momento comemoramos do jeito que deu. Ela de sua janela e eu da minha varanda. Tomamos café da manhã juntas, conversamos e choramos além de agradecermos o dia de hoje e com fé em dias melhores que estão por vir.

Dei banho nos cachorros, estudei um pouco li e fui dormir cedo.

Brasil teve 1.185 novas mortes registradas em razão do vírus nas últimas $24 \mathrm{H}$. Com isso já são 38.497 óbitos pela COVID-19 até o momento. 
quarta-feira, 10 de junho de 2020

Boa noite Molly.

Já observou que sempre falo com você à noite? É o momento de lembrar do dia, das coisas que estamos passando.

Tudo bem que nunca tem algo muito novo né, mas mesmo assim é bom escrever, colocar no papel as emoções, as dúvidas, o medo do que nos espera é uma forma de aliviar a alma. Até amanhã. 
quinta-feira, 11 de junho de 2020

\section{Prezado Sabiá,}

Eae, o fim está próximo. Hoje é o penúltimo dia do nosso encontro e amanhã se encerra nossa jornada.

Feriado Nacional e posso finalmente descansar, em termos; o prazo para entrega do TCC se encerra dia 15/06/2020. Tenho ficado um pouco tenso nesses dias ao imaginar o grande dia. O tema me deixa confortável, mas quanto a me filmar, me traz insegurança. Tenho que confessar que sou um pouco tímido.

Quando falo da minha timidez algumas pessoas estranham, não acreditam, pensam que é brincadeira, mas por baixo de tantas brincadeiras existe alguém tímido.

O dia de hoje foi bem agradável. Relaxei completamente e deixei o amanhã para resolver depois. 
Oi Belinha, hoje é o dia dos namorados, essa nossa conversa começou há um mês atrás porque um dos meus professores-nos deu a criação do diário como tarefa e hoje termina o prazo para que registrássemos o nosso cotidiano, então hoje seria nosso último encontro, certo? Só que não, iremos continuar nos encontrando Belinha, foi ótimo esse nosso tempo juntinhas, mas iremos continuar a conversar, ok?

Bom hoje comecei a treinar minha apresentação e acontecesse que enxuguei tanto nas falas que em 15 minutos falei 9 minutos, acredita, mas vida que segue, tenho até a segunda-feira para treinar, meu filho irá me ajudar a postar o vídeo, sou bem crua em questões tecnológicas, mas estou aprendendo. Estamos em junho e já seria hora de estarmos terminando o estágio, como será? ninguém sabe. Preciso treinar o máximo hoje, pois amanhã é sábado e minha sobrinha de 3 anos quer vir ficar aqui comigo um pouco, está com saudades da titia, ela se chama Lívia é muito linda e fogueteira, esperta, falante e brincamos igual duas crianças e ela sabe que me ganha quando fala assim "titia" a bobona aqui derrete toda, geralmente meu irmão traz ela pela manhã e ela só aceita ir embora com muito custo quando tem "pisca-pisca" no céu, kkk quer dizer estrelas, e ai fico morta porque ela não é fácil, mas eu a amo e é um dia maravilhoso quando vem.

Treinei bastante Belinha, vou jogar um pouquinho do jogo THE SIMS que eu tanto adoro e depois vou dormir, preciso rever essa questão do dormir, porque não durmo antes de uma da manhã e é ruim.

Beijos, tchau e até mais. 


\section{POSFÁCIO}

Somos movidos por tudo que fazemos, queremos e vivemos. E o que tudo isso nos trouxe de aprendizado? Seguem alguns testemunhos:

"Essa atividade foi de extrema relevância, pois me fez refletir sobre todos os problemas que temos e, para termos êxito sobre eles, precisamos nos envolver de corpo e alma; além disso, consegui ter uma noção da importância de cada pessoa no meu cotidiano."

Daniel Teixeira

“Acompanhei as notícias que relatavam índices crescentes de óbitos e infectados pelo COVID-19 e o diário serviu como válvula de escape para os sentimentos vividos neste período, confortando-me; foi uma experiência única na qual eu nunca me esquecerei."

Amanda da Silva

"No mês de maio a junho de 2020 nos foi proposto fazer uma atividade diferente; um diário contando como estava sendo o período de isolamento social. Esta atividade foi marcante e permitiu que exprimisse sentimentos que estavam sedimentados em mim."

Rafaela Costa

"De certa forma experimentamos um pouco do medo e incertezas vividas por Anne

Frank. Nosso isolamento é traduzido em ansiedade, frustração, ira e medo. Usar um diário nos trouxe uma ponta de esperança de que essa guerra pela saúde logo findará."

Agder da Silva

"Realizar a atividade do diário foi uma grata surpresa e realização, pois, pude perceber que foi um momento de autorreflexão em meio a pandemia; uma maneira produtiva de passar o tempo, trabalhar a ansiedade e me proporcionar autoconhecimento."

Simone Mendes

"Realizar um registro do meu dia-a-dia foi bastante desafiador, porém muito gratificante. Tive a oportunidade de refletir sobre os meus próprios sentimentos e pensamentos; pude também enxergar as pequenas atitudes de um modo diferente."

Fernanda Machado 


\section{BIBLIOGRAFIA}

FRANK, Anne (1993), Anne Frank: The Diary of a Young Girl, ISBN 9780553296983, Bantam Books;

GIES, Miep (2012), Anne Frank Remembered: The Story of the Woman Who Helped to Hide the Frank Family, ISBN 9781471109492, Simon and Schuster;

M. FRANK, Otto (2011), The Diary of a Young Girl: The Definitive Edition, ISBN 9780307807533, Random House Publishing Group. 